\title{
AOR
}

Selected Papers of \#AolR2020:

The $21^{\text {st }}$ Annual Conference of the

Association of Internet Researchers

Virtual Event / 27-31 October 2020

\section{VOICES FROM THE LOCKER ROOM: A QUALITATIVE ANALYSIS OF VOICE MESSAGES WITHIN ITALIAN NSFW GROUPS.}

\author{
Giovanni Boccia Artieri \\ University of Urbino Carlo Bo \\ Stefano Brilli \\ University of Urbino Carlo Bo \\ Elisabetta Zurovac \\ University of Urbino Carlo Bo
}

Private chats and private groups play an increasingly central role in everyday communication (Cruz and Harindranath 2020) carrying along with them peculiar practices and issues. If on one side this "turn to the private" in digital media seems to have mitigated the panic about privacy that followed various data scandals, it also fed a new alarm.

This menace is tied to the idea that something "wrong" may go on in places that elude public scrutiny and to the fact that these places are part of the everyday life thanks to messaging apps. For instance, at the beginning of 2019, in Italy, several newspapers (Zorloni 2019) exposed some Telegram groups used for sharing illicit pornographic material, and this media attention has had the undeniable merit of bringing this topic to the political agenda, leading, on April 2019, to the approval of a law against non consensual pornography. Moreover, accessing the internet through mobile devices such as the smartphone means that there is the possibility to maintain a perpetual contact (Katz and Aakhus 2002) with other chat members and to enjoy "not suitable for work" (NSFW) contents through the day reproducing a sort of locker room talk (Vaynmana, Sandbergb and Pedersen 2019).

However, besides the risks related to the growing number of spaces eluding public scrutiny, the pervasive presence of IMs shows also that interactions with a higher level of self-disclosure such as voice messages are spreading as well through different platforms (i.e. WhatsApp, Telegram, Instagram, Facebook Messenger, WeChat). 
After a first phase where texting got over phone calls (GFDS 2018), research is showing that voice messages shared within chats (König 2019) seems to be the uprising. While a consistent volume of research on computer-mediated spoken interaction (CMSI) shreds light on the implications of synchronous voice communication (Jenks 2014, Jiang et al. 2019) there is still space for the investigation of the use of voice messages within Instant Messaging (IM) platforms.

The aim of this research was to investigate the relation between privacy and exposure and therefore between spectatorship and participation - within Italian NSFW online groups on Telegram through the analysis of voice messages produced.

\section{Research questions and methodology}

Our research aims to understand the use of voice messages in NSFW group chats, where participation may involve social stigma. More specifically we look at the interactional possibilities afforded by voice messages, at the style of self-disclosure associated with them and at the emerging issues in the moderation process of audio contents (Jiang et al. 2019). The choice to focus on Telegram closed group chats dedicated to sharing and discussing adult entertainment follows three motivations.

Firstly, this kind of groups are growing in number and are subjects of a recent wave of concern within Italian media outlets (Bainotti \& Semenzin, forthcoming). Secondly, these spaces are usually understood as prevalently anonymous contexts; therefore, the disclosure afforded by voices messages - particularly in terms of gender recognition may acquire specific meanings. Thirdly, the nature of the contents shared in these groups places the issue of moderation as central.

Therefore, we investigate three research questions:

1) What kind of interactions are enacted by voice messages?

2) What kind of self-disclosure is performed through voice messages?

3 ) Which challenges emerge in the moderation of voice messages?

For this research, we are carrying out a qualitative content analysis of group interactions combined with in-depth interviews with groups' moderators. Although some recent studies are exploring big-data approaches in researching messaging apps (Resende et al. 2019), ethnographic approaches are revealing as particularly suited in dealing with the technical and ethical limitations in studying conversations in chat apps (Baulch et al. 2020; Milan \& Barbosa 2020).

We selected the groups to research from a public list of adult-oriented Telegram groups provided by the principal Italian website specialized in indexing Telegram groups and channels. We then joined all the active groups in the list (45 groups, January 2020) and selected ten groups with the highest ratio between the number of voice messages and photos uploaded. In this way, we could have a hint of which groups presented the highest level of voice interaction. 
For this study, we planned three phases of the data collection. First, we engaged in listening to all the voice messages uploaded by group members. To this end, we used the "Export Chat History" function available to every user. We then listened to all the messages to understand the styles and functions of voice interaction. Approximately more than 50 hours of voice messages were listened to by the researchers. Second, we plan to perform a qualitative content analysis of voice messages, focusing on a single week of interactions in every one of the ten groups. Every message will be coded considering its embeddedness in the conversation. The content analysis will look at 1) interactive function of the message (addressed to the group, addressed to a single person); 2) level of self-disclosure (if the message recounts details of the member private life); 3) topic (porn-related, group-related, etc.); 4) sonic style (whispering, normal voice, loud voice); 5) utterance situation (possible or not possible to write). Third, we are going to conduct ten in-depth interviews with groups moderators, to elicit their individual use/non-use of voice messages and the moderations practices regarding audio contents.

\section{Preliminary results and expected outcomes}

The research is still ongoing. However, the exploratory phase of the study has already suggested some circumstances that lead users to prefer using voice messages over text, gifs and static images. Contingent (not being able to text) or literacy-related reasons appear less important than the need to establish affective inclusion and identification through one's own voice. Members use voice messages to enhance affective inclusion, that is to mark a sub-category of top members that share a "relational oral space". Moreover, voice messages serve also as a means for women to be identified as "not fake", and for all members to be identified as "not ashamed". In the next phases of the research, we expect to inspect how the moderation process act towards this gender imbalance.

\section{References}

Bainotti, L., \& Semenzin, S. (forthcoming). The use of Telegram for non-consensual dissemination of intimate images: gendered affordances and the construction of masculinities. Social Media+ Society.

Baulch, E., Matamoros-Fernández, A., \& Johns, A. (2020). Introduction: Ten years of WhatsApp: The role of chat apps in the formation and mobilization of online publics. First Monday, 25(1).

Cruz, E. G., \& Harindranath, R. (2020). WhatsApp as 'technology of life': Reframing research agendas. First Monday, 25(12). doi: 10.5210/fm.v25i12.10405. 
GFDS - Society for German Language (2018). Linguistic Communication in the Digital World. A representative survey conducted by forsa. Available at: https://gfds.de/wpcontent/uploads/2018/03/Sprachliche-Kommunikation-in-der-digitalen-Welt-2018.pdf.

Katz, J. E., \& Aakhus, M. (2002). Perpetual Contact: Mobile Communication, Private Talk, Public Performance. Cambridge University Press, USA.

Jenks, C. J. (2014). Social Interactions in Second Language Chat Rooms. Edinburgh University Press. ISBN: 978-0-7486-4948-8.

Jiang, J. A., Kiene, C., Middler, S., Brubaker, J. R., \& Fiesler, C. (2019). Moderation Challenges in Voice-based Online Communities on Discord. Proceedings of the ACM on Human-Computer Interaction, 3(CSCW), 1-23.

König, K. (2019). Narratives 2.0 A Multi-Dimensional Approach to Semi-Public Storytelling in WhatsApp Voice Messages. Journal für Medienlinguistik, 2(2), 30-59. https://doi.org/10.21248/jfml.2019.10

Milan, S., \& Barbosa, S. (2020). Enter the WhatsApper: Reinventing digital activism at the time of chat apps. First Monday, 25(12).

Resende, G., Melo, P., Sousa, H., Messias, J., Vasconcelos, M., Almeida, J., \& Benevenuto, F. (2019, May). (Mis) Information Dissemination in WhatsApp: Gathering, Analyzing and Countermeasures. The World Wide Web Conference, 818-828.

Vaynman, M. J., Sandberg, S., \& Pedersen, W. (2019). Locker room talk: male bonding and sexual degradation in drinking stories. Culture, Health \& Sexuality. DOI: 10.1080/13691058.2019.1670864.

Zorloni, M. (2019, Jan). Uscite le minorenni. Wired. Available at: https://www.wired.it/internet/web/2019/01/23/telegram-chat-stupro-virtuale-minoristalking-revenge-porn/ 